SHORT REPORT

\title{
A locus for spondylocarpotarsal synostosis syndrome at chromosome 3pl4
}

\author{
C Steiner, N Ehtesham, K D Taylor, E Sebald, R Cantor, L M King, X Guo, T Hang, M S Hu, J-R Cui, \\ B Friedman, D Norato, J Allanson, C Honeywell, G Mettler, F Field, R Lachman, D H Cohn, \\ D Krakow
}

J Med Genet 2004;41:266-269. doi: 10.1136/jmg.2003.012252

Spondylocarpotarsal synostosis syndrome is a rare autosomal recessive disorder characterised by vertebral fusions, frequently manifesting as an unsegmented vertebral bar, as well as fusions of the carpal and tarsal bones.

In a study of three consanguineous families and one nonconsanguineous family, linkage analysis was used to establish the chromosomal location of the disease gene. Linkage analysis localised the disease gene to chromosome $3 p 14$. A maximum lod score of $6.49(q=0)$ was obtained for the marker at locus D3S3532 on chromosome $3 p$. Recombination mapping narrowed the linked region to the $5.7 \mathrm{cM}$ genetic interval between the markers at loci D3S3724 and D3S1300. A common region of homozygosity was found between the markers at loci D3S3724 and D3S1300, defining a physical interval of approximately 4 million base pairs likely to contain the disease gene.

Identification of the gene responsible for this disorder will provide insight into the genes that play a role in the formation of the vertebral column and joints.

S pondylocarpotarsal synostosis (SCT) syndrome, also known as congenital synspondylism (OMIM \#272460), is primarily a disorder of abnormal segmentation of the vertebral bodies and joint fusions in the hands and feet. The term spondylocarpotarsal synostosis syndrome was first used by Langer $e t a l^{11}$ to describe the predominant clinical and radiographic findings in the disorder, and at least 20 cases have been described in the literature. ${ }^{7}$ The phenotype is distinguished from other disorders of vertebral segmentation, such as spondylocostal dysplasia and spondylothoracic dysplasia, because of the lack of rib anomalies and the presence of carpotarsal fusions. The vertebral abnormalities can be seen in the neonatal period and appear to result from unilateral failure of segmentation of the vertebral bodies, resulting in progressive scoliosis. Carpal synostosis usually involves the capitate-hamate and lunate-triquetrum bones, and the tarsal coalitions may lead to club feet. Other variable findings in this disorder include sensorineuronal or mixed hearing loss, cervical spine instability, cleft palate, pes planus, defective dentition, and facial dysmorphism. ${ }^{4} 719$

\section{MATERIALS AND METHODS}

We studied four families with SCT syndrome; three consanguineous and one non-consanguineous. One of the consanguineous families with SCT syndrome and eye abnormalities that included lens opacities, rarefaction of the retinal pigmentation, and narrowing of the retinal vessels was reported by Steiner et al in 1999 (fig 1, International Skeletal Dysplasia Registry reference number R99-438).
Radiographic findings in the affected individuals showed unsegmented thoracic vertebrae with a unilateral bar and carpal fusions. A second family, R03-062 (fig 1), was reported by Honeywell et al in 2002. In addition to many of the characteristic findings of SCT syndrome, the proband in this family manifested short stature, with radiographic evidence of epiphyseal delay. The pedigrees of the two other families studied, one consanguineous and one non-consanguineous (R00-008 and R00-084) are also shown in fig 1. A summary of the clinical and radiographic findings in affected individuals from these families is presented in table 1 .

The characteristic radiographic findings of SCT syndrome, vertebral and captitate-hamate fusions, were present in all affected individuals studied and are shown in fig 2 . In addition, an MRI of the spine was obtained on another individual with SCT (R03-038A). The thoracic region showed small, irregular vertebral bodies and absence of the nucleus pulposus, suggesting that the abnormalities of the spine reflect a defect of segmentation of the vertebral bodies early in development.

Under an institutional review board approved protocol, informed consent was obtained from all affected and unaffected individuals in the families under study. Blood was collected and DNA extracted by standard protocols. An initial genome scan failed to identify a linked region among about 500 markers typed in pedigree R99-438. A second genomewide scan was performed on individuals in pedigree R00-008, using the 400 markers from the ABI Prism Linkage Mapping set (MD 10, version 2.5; Applied Biosystems, Foster City, CA, USA). Each $15 \mu \mathrm{l}$ polymerase chain reaction contained $25 \mathrm{ng}$ genomic DNA, $200 \mu \mathrm{mol} / \mathrm{l}$ dNTPs, $0.33 \mu \mathrm{mol} / \mathrm{l}$ each primer, $0.5 \mathrm{U}$ AmpliTaq Gold DNA polymerase (PE Biosystems, Foster City, CA, USA), and $1.5 \mathrm{mmol} / \mathrm{l} \mathrm{MgCl}_{2}$. PCR was carried out using a Perkin Elmer 9700 GeneAmp Thermocycler as follows: 10 minutes at $95^{\circ} \mathrm{C}$; 35 cycles of 30 seconds at $94^{\circ} \mathrm{C}, 75$ seconds at $55^{\circ} \mathrm{C}$ and 15 seconds at $72^{\circ} \mathrm{C} ; 10$ minutes at $72^{\circ} \mathrm{C}$. PCR products were resolved by capillary electrophoresis using an ABI model 3100 automated DNA sequencer. Genotypes were analysed using the ABI Genotyper 2.5 software package. We checked for Mendelian errors using Pedcheck. ${ }^{13}$ Two point lod scores were calculated using Mendel (version 4.0). ${ }^{29}$ Initial evidence of linkage in family R00-008 was obtained for the marker at locus D3S1300, which yielded a maximum lod score of 2.33 $(\theta=0)$. Although genotypes were determined for the marker at locus D3S1300 in the original genome scan performed for family R99-438, the mother's analysis was not informative at this locus and there were recombinations in two of the five

Abbreviations: FGF, fibroblast growth factor; FGFR, FGF receptor; $\mathrm{SCT}$, spondylocarpotarsal synostosis 

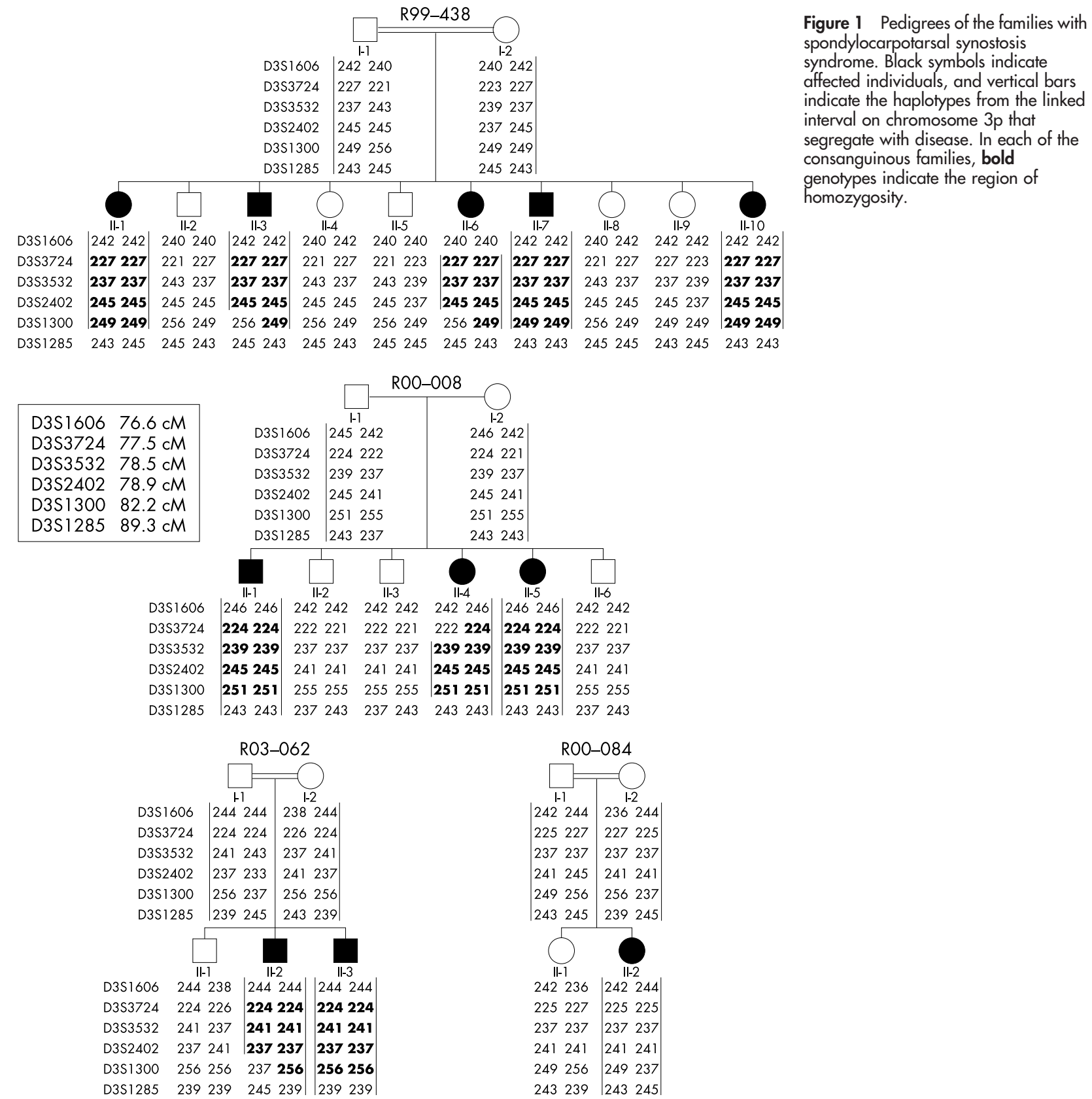

paternal alleles. Thus, linkage to the region was not initially detected.

Additional polymorphic markers in the region were then tested in all of the families. A maximum lod score of 6.49 $(\theta=0)$ was obtained for the marker at locus D3S3532 at chromosome 3 pl4 (table 2). Haplotypes across the region in each family were created by parsimony (fig 1). A recombinant event in individual II-4 in pedigree R00-008 defined the centromeric limit at the marker at locus D3S3724. Recombinations at the marker at locus D3S1300 in individuals II-3 and II-6 from family R99-438 and individual II-2 in family R03-062 were used to define the telomeric limit of the linked interval. Recombination mapping thus localised the disease gene within the $4.7 \mathrm{cM}$ genetic interval defined by the markers at loci D3S3724 and D3S1300.

\section{RESULTS AN D DISCUSSION}

Under the assumption that affected individuals in the consanguineous families would be homozygous by descent for the mutations producing SCT syndrome, the genomic interval containing the disease gene could be refined to the smallest common interval of homozygosity. This interval, which was flanked by the markers at loci D3S3724 and D3S1300, is estimated to be approximately 4000000 base pairs long. Examination of the human genomic sequence databases (NCBI and UCSC) showed that there are 12 known genes and 24 hypothetical genes in the region. Known genes include $S E F$, which encodes a ligand similar to fibroblast growth factor (FGF). SEF has been shown to have an inhibitory effect on FGF receptor (FGFR) signalling. ${ }^{8}$ FGFs are expressed in the apical ectodermal ridge and are involved in the patterning of the skeleton, ${ }^{16}$ and FGF signalling, specifically through FGFR3, is well documented in cartilage and chondrocytes. ${ }^{5}$ Furthermore, heterozygosity for mutations in the FGFR3 gene produces a spectrum of osteochondrodysplasia phenotypes. ${ }^{18}$ Thus, a ligand similar to FGF and one that has a known effect on FGFR signaling could have a role in the developing skeleton. HESXI, a member of the 


$\begin{aligned} & \text { Table } 1 \\ & \text { individuals }\end{aligned}$
ind

paired-like class of homeobox genes that is essential for pituitary and forebrain development, is also within the linked interval. ${ }^{2}$ Heterozygosity for mutations in this gene produce septo-optic dysplasia, ${ }^{17}$ making it unlikely that defects in HESX1 produce SCT syndrome. Similarly, ACOX2 is an unlikely candidate because absence of the gene product is seen in Zellweger syndrome. ${ }^{1}$ Other known genes in the linked interval include APPL, ASP14, ARF4, FLNB, RPP14, $P D H B, D N A S E I L 3, T U 3 A$, and FAM $3 D$. Little is known regarding the function of any of these genes in skeletal development, so they remain candidate genes simply based on their chromosomal location. Among the 24 hypothetical genes in the linked interval, the expression of some is supported by homology to known expressed sequence tags, while others have been identified exclusively by gene prediction algorithms.

The most favourable candidate genes are expected to be those that are expressed early in development, specifically during the embryonic period when sclerotomes develop and segment into vertebral bodies. ${ }^{14}$ This hypothesis is supported by MRI of the spine in SCT syndrome (fig 3 ) showing the lack of a nucleus pulposus and indicating that, at the affected segment levels, fibrous discs are not formed between the vertebral bodies. As these events normally occur during the fourth week of embryogenesis, the normal function of the

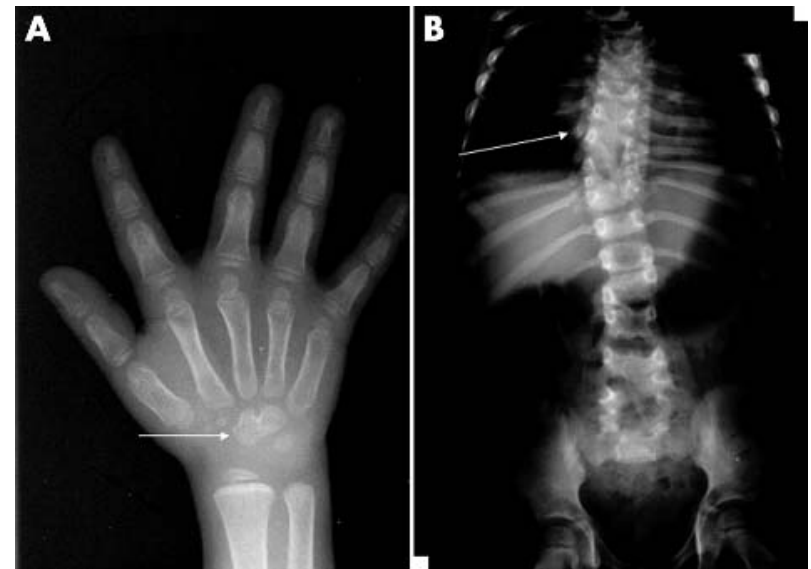

Figure 2 Radiographs of the hands and spine from individual II-1, family R00-008. (A) Right hand radiograph showing capitate-hamate fusion (arrow). (B) AP radiograph of the spine showing massive vertebral fusions of thoracic vertebrae 5-12 (arrow).

SCT syndrome gene product is likely to be required at this stage of development.

Patients with SCT syndrome also have characteristic fusions of the carpal and tarsal bones, so the defective gene has a probable role in joint morphogenesis. Joint morphogenesis is a complex, multi-step process that involves apotosis and ultimately cavitation to create a joint space. ${ }^{12}$ Initiators of joint morphogenesis include NOGGIN and GDF5. ${ }^{6}$ Heterozygosity for mutations in the NOGGIN gene produces multiple synostosis syndrome, another disorder that includes joint fusions. ${ }^{6}$ During joint formation, NOGGIN regulates the expression of growth differentiation factor 5 (GDF5). Numerous other genes are involved in joint formation, some of which include GDF6, GDF7, WNT14A, and WNT5A. ${ }^{3}$ WNT5A is localised to chromosome $3 \mathrm{q} 14$, near the SCT syndrome disease gene interval. Thus, when the initial linkage was obtained at for the marker at locus D3S1300, we considered WNT5A to be a good disease gene candidate. However, sequence analysis of the coding exons and flanking splice junctions of WNTSA in affected individuals from the SCT syndrome families did not identify any sequence changes, excluding structural mutations in WNTSA as the cause of SCT syndrome. Subsequent fine structure genetic mapping also excluded WNTSA as the disease gene based on a recombination seen for the marker at locus D3S3724 in individual II-4 from family R00-008 (fig 1).

In addition to vertebral anomalies and joint fusions, SCT syndrome has other physical manifestations, including short stature, hearing, vision, and dental abnormalities, suggesting that the disease gene has an expression pattern beyond vertebral segmentation and joint morphogenesis. The short

Table 2 Two-point lod scores at chromosome 3p14 loci for families with SCT

\begin{tabular}{llllllll}
\hline \multirow{2}{*}{$\begin{array}{l}\text { Marker } \\
\text { at locus }\end{array}$} & \multicolumn{2}{l}{ LOD Score at $\boldsymbol{\theta}=$} \\
\cline { 2 - 8 } & $\mathbf{0 . 0 0}$ & $\mathbf{0 . 0 1}$ & $\mathbf{0 . 0 5}$ & $\mathbf{0 . 1}$ & $\mathbf{0 . 2}$ & $\mathbf{0 . 3}$ & $\mathbf{0 . 4}$ \\
\hline D3S1606 & -5.52 & -1.62 & 0.71 & 1.32 & 1.35 & 0.89 & 0.34 \\
D3S3724 & 2.98 & 3.87 & 4.07 & 3.75 & 2.81 & 1.75 & 0.71 \\
D3S3532 & 6.49 & 6.36 & 5.81 & 5.11 & 3.67 & 2.23 & 0.87 \\
D3S2402 & 4.28 & 4.21 & 3.86 & 3.42 & 2.47 & 1.48 & 0.54 \\
D3S1300 & -4.17 & -1.24 & 0.53 & 1.02 & 1.08 & 0.76 & 0.30 \\
D3S1285 & -7.82 & -3.41 & -0.45 & 0.48 & 0.85 & 0.63 & 0.26 \\
\hline
\end{tabular}




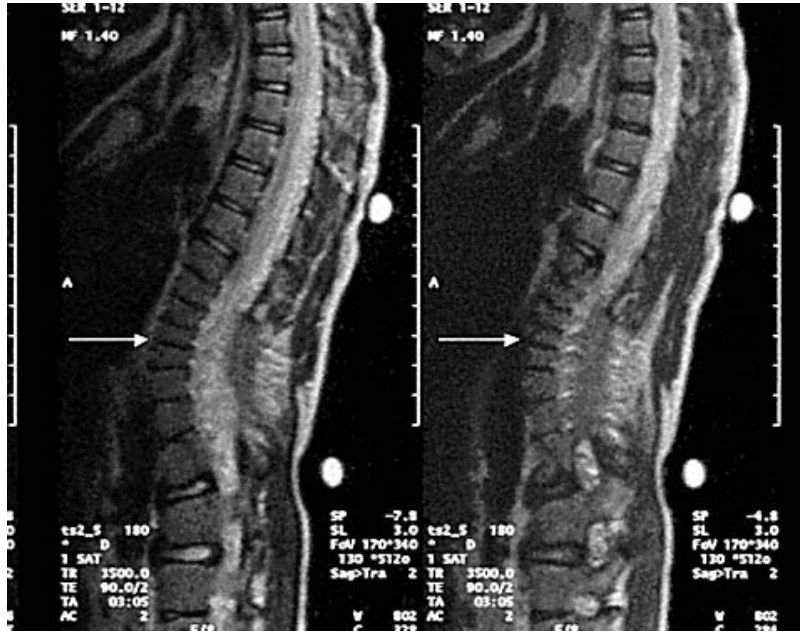

Figure $3 \mathrm{MRI}$ from an affected individual with spondylocarpotarsal syndrome (R03-038) showing abnormal shaped vertebral bodies (arrow) and lack of the nucleus pulposus in the thoracic region.

stature that characterises SCT syndrome, together with the observation of epiphyseal delay in at least one family, ${ }^{7}$ suggests a possible defect in endochondral ossification. This in turn predicts that the defective gene will be expressed in growth plate cartilage. Of the 36 genes (including hypothetical genes) in the interval, public databases show expression in cartilage for APPL, ARF4, FLNB, RPP14, and PDHB. To identify the disease gene, candidate genes of the highest priority for mutation analysis will be those expressed in cartilage.

We conclude that SCT is a complex disease of vertebral segmentation, joint morphogenesis, and growth. In the four families studied, the disease gene is localised to chromosome 3 pl4, and there is no evidence of locus heterogeneity. The identification of the disease gene will lead to a further understanding of vertebral segmentation and joint formation.

\section{ELECTRONIC DATABASE INFORMATION}

Online Mendelian Inheritance in Man (OMIM) (for SCT syndrome OMIM 272460), http://www.ncbi.nlm.nih.gov/ Omim/

NCBI Map Viewer (for genes and polymorphic markers on chromosome 3pl4). http://www.ncbi.nlm.nih.gov/cgi-bin/ Entrez/map_search/

UCSC Human Genome Project Working draft, (for genes on chromosome 3pl4). http://genome.ucsc.edu/

\section{ACKNOWLEDGEMENTS}

We thank the family members who participated in the study. We also thank M A Priore and G Rose of the International Skeletal Dysplasia Registry for their assistance in the collection of the samples. This work was supported by NIH grant HD22657 to D H Cohn and D Krakow, a grant from the Drown Foundation to D Krakow and by NIH grant RR00425 to the Cedars-Sinai/UCLA General Clinical Research Center.

\section{Authors' affiliations}

C Steiner, D Norato, Medical Genetics Department, Medical Sciences School, State University of Campinas, Campinas, São Paulo, Brazil N Ehtesham, K D Taylor, L M King, X Guo, T Hang, M S Hu, J-R Cui, F Field, R Lachman, D H Cohn, D Krakow, Department of Pediatrics, Cedars-Sinai Medical Center, Los Angeles, CA, USA
E Sebald, D Krakow, Department of Obstetrics and Gynecology, Cedars-Sinai Medical Center, Los Angeles, CA, USA

R Cantor, D H Cohn, Department of Human Genetics, David Geffen School of Medicine at UCLA, Los Angeles, CA, USA

R Lachman, Department of Radiology, David Geffen School of Medicine at UCLA, Los Angeles, CA, USA

R Cantor, D H Cohn, Department of Pediatrics, David Geffen School of Medicine at UCLA, Los Angeles, CA, USA

D Krakow, Department of Obstetrics and Gynecology, David Geffen

School of Medicine at UCLA, Los Angeles, CA, USA

B Friedman, Private Practice, Sacramento, CA, USA

J Allanson, G Mettler, C Honeywell, Eastern Ontario Regional Genetics Program, OHtawa, Canada

Conflict of interest: none declared.

Correspondence to: Dr D Krakow, Cedars-Sinai Medical Center, 8700 Beverly Boulevard, SSB-369, Los Angeles, CA 90048, USA;

deborah.krakow@cshs.org

Received 11 July 2003

Accepted for publication 26 August 2003

\section{REFERENCES}

1 Baumgart E, Vanhooren JC, Fransen M, Marynen P, Puype $M$, Vandekerckhove J, Leunissen JA, Fahimi HD, Mannaerts GP, van Veldhoven PP. Molecular characterization of the human peroxisomal branched-chain acyl-CoA oxidase: cDNA cloning, chromosomal assignment, tissue distribution, and evidence for the absence of the protein in Zellweger syndrome. Proc Natl Acad Sci USA 1996;93:13748-53.

2 Brickman JM, Clements M, Tyrell R, MCNay D, Woods K, Warner J, Stewart A, Beddington RS, Dattani M. Molecular effects of novel mutations in Hesxl / HESX1 associated with human pituitary disorders. Development 2001; 128:5189-99.

3 Church V, Nohno T, Linker C, Marcelle C, Francis-West $P$. Wnt regulation of chondrocyte differentiation. J Cell Sci 2002;115:4809-18.

4 Coelho K-EFA, Ramos ES, Felix TM, Martelli L, de Pina-Neto JM, Niikawa N. Three new cases of spondylocarpotarsal synostosis syndrome: clinical and radiographic studies. Am J Med Genet 1998;77:12-15.

5 Dailey L, Laplantine E, Priore R, Basilico C. A network of transcriptional and signaling events is activated by FGF to induce chondrocyte growth arrest and differentiation. J Cell Biol 2003;161:1053-66.

6 Francis-West PH, Parish J, Lee K, Archer CW. BMP/GDF-signalling interactions during synovial joint development. Cell Tissue Res 1999;296:111-19.

7 Honeywell C, Langer L, Allanson J. Spondylocarpotarsal synostosis with epiphyseal dysplasia. Am J Med Genet 2002;109:318-22.

8 Kovalenko D, Yang X, Nadeau RJ, Harkins LK, Friesel R. Sef inhibits fibroblast growth factor signaling by inhibiting FGFR1 tyrosine phosphorylation and subsequent ERK activation. J Biol Chem 2003;278:14087-91.

9 Lange K, Weeks D, Boehnke M. Programs for Pedigree Analysis: MENDEL, FISHER, and dGENE. Genet Epidemiol 1988;5:471-72.

10 Lange K, Cantor R, Horvath S, Perola M, Sabatti C, Sinsheimer J, Sobel E. Mendel version 4.0: a complete package for the exact analysis of discrete traits in pedigree and population data sets. ASHG San Diego. Am J Hum Gen Oct $2001 ; 69: 504 \mathrm{~A}$

11 Langer LO Jr, Gorlin RJ, Donnai D, Hamel BCJ, Clericuzio C. Spondylocarpotarsal synostosis syndrome (with or without unilateral unsegmented bar). Am J Med Genet 1994;51:1-8.

12 Mariani FV, Martin GR. Deciphering skeletal patterning: clues from the limb. Nature 2003;423:319-25.

13 O'Connell JR, Weeks DE. PedCheck: a program for identification of genotype incompatibilities in linkage analysis. Am J Hum Genet 1998;63:259-66.

14 Pourquie O, Kusumi K. When body segmentation goes wrong. Clin Genet 2001;60:409-416.

15 Steiner CE, Torriani M, Norato DYJ, Marques-de-Faria AP. Spondylocarpotarsal synostosis with ocular findings. Am J Med Genet 2000;91:131-4.

16 Sun X, Mariani FV, Martin GR. Functions of FGF signalling from the apical ectodermal ridge in limb development. Nature 2002;418:501-8.

17 Tajima T, Hattorri T, Nakajima T, Okuhara K, Sato K, Abe S, Nakae J, Fujieda K. Sporadic heterozygous frameshift mutation of HESXI causing pituitary and optic nerve hypoplasia and combined pituitary hormone pituitary and optic nerve hypoplasia and combined pituitary hormone
deficiency in a Japanese patient. J Clin Endocrinol Metab 2003;88:45-50.

18 Vajo Z, Francomano CA, Wilkin DJ. The molecular and genetic basis of fibroblast growth factor receptor 3 disorders: the achondroplasia family of skeletal dysplasias, Muenke craniosynostosis, and Crouzon syndrome with acanthosis nigricans. Endocr Rev 2000;21:23-39.

19 Ventruto V, Catani L. Progressive scoliosis by unilateral unsegmented fusion bar, foot deformity, joint laxity, congenital inguinal herniae, peculiar face. Am J Med Genet 1986;25:429-32. 